\title{
Três leituras sensoriais na publicidade
}

\author{
Kati Eliana Caetano \\ Universidade Tuiuti do Paraná
}




\section{Resumo}

Este ensaio efetua a análise de três campanhas publicitárias, apontando o papel dos traços sensoriais na determinação do percurso de leitura do texto e na construção dos efeitos de sentido. A partir dessa abordagem analítica, discute a relação contratual entre enunciador e enunciatário pressuposta nas estratégias discursivas adotadas e duas lógicas de apreensão das mesmas, baseadas na emoção e justificadas pela razão.

\section{Palavras-chave}

linguagem publicitária, percepção sensorial, paixões

\section{Abstract}

This essay analyses three advertising campaigns, aiming the role of the sensorial traits in the determination of the course of reading of the text and in the construction of the meaning effects. Starting from that analytic approach, it discusses the contractual relationship between enunciate and enunciatee presupposed in the adopted discursive strategies and two logics of apprehension of the same ones, based on the emotion and justified by the reason.

\section{Key words}

advertising language, sensorial perception, passion 


\section{A metáfora renovada - FlowerbyKenzo}

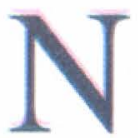

ormalmente a relação entre a publicidade e a embalagem de um produto se estabelece em termos de expansão e condensação: a publicidade desdobra, descreve a narratividade pressuposta na forma condensada da embalagem. $\mathrm{Na}$ embalagem do perfume lançado recentemente pela grife Kenzo, Flower, descobre-se o processo contrário. Na embalagem está exposto, em etapas cuidadosamente trabalhadas, o que na publicidade visual é uma incógnita.

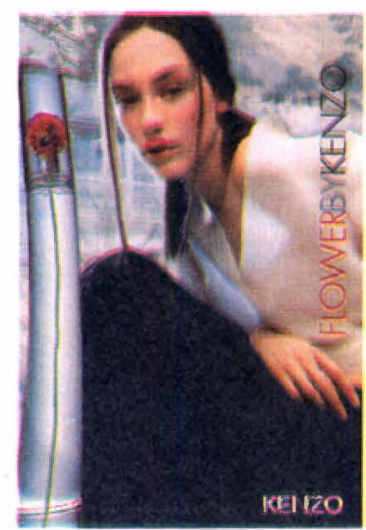

Figura 1 - Reprodução do post-card de divulgaçāo nacional do perfurne.

A publicidade apresenta uma mulher: longilínea, esguia, sentada em postura levemente curvada lembrando o movimento imprimido à forma do frasco, o rosto maquiado segundo uma estética facial oriental, asiática com certeza, embora a modelo seja ocidental, e, obviamente, o rosto porcelanizado. Não há legenda, não há mensagem verbal, além da alusão explícita ao nome do perfume, acom- 
panhado da grife, e à nova fragrância. A maquiagem faz reduzir o tamanho da boca, tornando-a arredondada, também no estilo da iconografia feminina asiática. Ao mesmo tempo, o espectador é levado a ver tentativas de uma evocação do semblante de Mona Lisa na modelo assim preparada, sobretudo pela configuração da boca e pelo olhar dirigido para fora da foto, numa convocação claramente enunciativa do enunciatário. De resto, a peça publicitária tenta manter a mesma aura de mistério: não se sabe bem o que a modelo representa, o que evoca, além, obviamente, da mensagem evidente de um bom gosto que esse tipo de texto está sempre querendo nos passar.

A embalagem, ao contrário, ganha em excesso de informação o que no cartão postal foi concisão. A caixa que embala o frasco apresenta em cada uma de suas faces o estágio de desabrochamento. de uma flor: o botão fechado numa primeira tomada; em seguida, levemente aberto; depois se abrindo efetivamente em flor, as pétalas vermelhas bem delineadas e, por fim, a flor em sua plenitude.

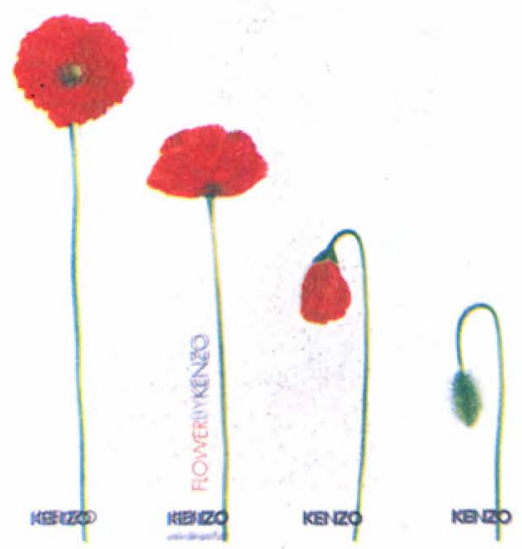

Figura 2 - Fotos da caixa do perfume FlowerbyKenzo.

A seqüência de transformações revela, de imediato, um percurso evidente: o perfume para todas as idades. Outras leituras, menos comuns, podem ser feitas, como a da própria preparação do perfume até o refinamento do aroma, exalado pela flor madura. 
Cada etapa do processo transformativo alude à perda de valores e à conquista de outros. A qualidade tenra, esverdeada, meio sem vida, mas ao mesmo tempo singela, do botão-cápsula é substituída pela afirmação da cor vermelha presente nas formas bem delineadas das pétalas. Linhas e cor são, portanto, os componentes expressivos dessa passagem da inocência (no sentido também negativo de ausência de certos traços semânticos) à pregnância da flor adulta, com aroma, tonalidade e formas definidas. Lembre-se ainda da simbologia da cor vermelha em várias culturas, seja ela relacionada à sensualidade, à guerra ou aos tumultos passionais e a associação entre a cor selecionada e dois tipos de completude, a do perfume e a da idade adulta.

Mas a plenitude cultuada tem seu pico e seu decréscimo. Uma vez atingido o apogeu, a sequiência das etapas é considerada em termos de perdas. Não se elogia, no mundo dos perfumes, assim como na moda de um modo geral, a velhice, pois ela só se configura pela perda de valores e não pela conquista de outros positivamente definidos. Por isso, o processo de formação da flor se interrompe no momento apoteótico. Não vemos as pétalas despetalando, caindo ou murchando como nos girassóis de Van Gogh (Barros, 1986). Este mundo está banido do horizonte publicitário enquanto universo de apreciação.

Reatualização de uma metáfora óbvia, tradicional, a da associação da flor com a mulher, o design da embalagem procura mostrar um novo enfoque - a flor não é a rosa, símbolo cristalizado da mulher do desejo (quem não se lembra da publicidade de sabonetes - nove entre dez estrelas de Hollywood, preferem Lux protagonizado pela artista envolvida em imagens multicoloridas de rosas?). Trata-se de uma flor exótica, (possivelmente lanternas chinesas, afirma a florista), que, em sua aparência, guarda semelhança com a papoula, flor que traz entre os sentidos a ela aludidos a idéia do entorpecimento provocado pelo ópio.

A retomada do estereótipo - flor e mulher - é singularizada pela especificidade de uma certa flor e o retoque de uma ambiência obtida pelo design do vidro, pela textura acetinada da caixa e pelo intertexto da publicidade audiovisual, além, obviamente, do toque ori- 
ental isotopicamente reiterado: o estilista $\mathrm{Kenzo}$, a mulher asiática, a flor exótica.

Embora repetido à exaustão, tais temas e figuras continuam configurando o universo da perfumaria, para não dizer da moda, criando a impressão de que por ali se pode aceder a um mundo de sonhos, euforia e alienação dos problemas reais. Por que o perfume de Kenzo, apesar de renovar a tradição do déjà $v u$, narrativiza o percurso da flor se formando?

As transformaçôes da flor expostas na sequiência orientam um percurso do olhar que perscruta cada detalhe da embalagem exterior, obrigando o consumidor a uma manipulação tátil da caixa que a envolve totalmente e que se detém, com certo gozo, em cada uma de suas quatro faces. Ela não é mais uma caixa, é o próprio objeto de admiração, o continente transformado em conteúdo consumível, obra de arte tão valorizável, atrativa, sedutora quanto o é o vidro, e, por extensão, o perfume.

Dois traços importantes caracterizam a organização visual da embalagem: a discretização das imagens e a circularidade gestual que a contemplação das mesmas impõe. Não por acaso, a seleção dessas figuras, pertencentes respectivamente à composição gráfica e à disposição das unidades (Floch, 1987), reitera as mensagens das figuras de conteúdo, a categoria: singularidade (flor) e envolvimento inebriante (perfume/ópio). Embora a justificativa obtida em perfumaria especializada seja a de que a escolha da papoula se deve ao fato de esta flor não ter perfume, podendo, em conseqüência, representar hic et nunc o novo aroma lançado pela grife, não há dúvida de que antes do perfume, o que se retém da imagem selecionada é a associação com o efeito do ópio que as sementes dessa planta produzem, insinuada sobretudo pela presença do botão em cápsula, marca inconfundível dessa espécie de vegetal.

Se o vidro do perfume deixou, há muito tempo, de ser uma chamada para o produto, tornando-se ele próprio a mercadoria, objeto de adorno e contemplação (mesmo, para algumas pessoas, quando o perfume acaba e o frasco está vazio), nesse caso a caixa de papelão não é mais descartável. Ela faz parte do acervo artístico da casa, junto com outros objetos expostos apenas em espaço íntimo, servindo à contemplação do possuidor, que nela vê sincretizada a repre- 
sentação do (seu) gosto estético e da (sua) distinção que o aroma cuidadosamente escolhido lhe proporciona.

Evidencia-se o valor reificado da embalagem, que longe de atrair para o produto converte-se duplamente em fonte de admiração e objeto de contemplação narcisística, que atrai o olhar tanto quanto reflete sua seletividade.

Ao contrário das outras embalagens, em que a carga semântica estético-passional está concentrada no frasco, o perfume de Kenzo eleva a um certo grau de saturação a estereotipia das imagens. Dentro da caixa, uma carta, em papel fino, parafinado, contém. uma mensagem em delgadas letras pretas, tão cristalizada em seu conteúdo quanto a evocação visual da flor: $O$ poder de uma flor singular, forte, pura e sensual.

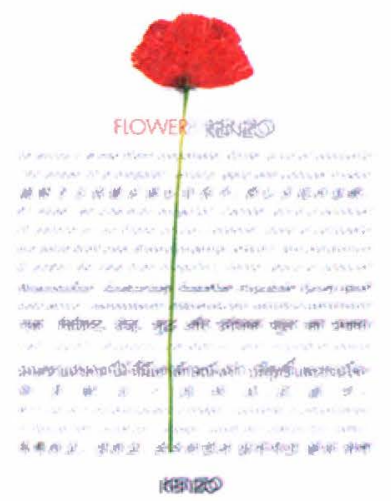

Figura 3 - Foto do encarte apresentado na embalagem.

O mesmo texto aparece escrito em dezesseis línguas, de escrita alfabética e ideográfica. Voltadas, sem dúvida, ao público heterogêneo que o mercado globalizado garante, as mensagens estão dispostas numa seqüência em que a escrita deixa de ser símbolo fonético para se tornar ícone; uma espécie de sombra cinza reticulada que emoldura a parte central do papel e constitui o cenário de fundo sobre o qual a mesma flor vermelha, em seu penúltimo estágio (portanto quase madura) está posicionada.

Assim como as figuras da expressão visual reportavam à idéia da singularidade, as figuras do conteúdo do discurso verbal tam- 
bém acentuam esse valor semântico, agora claramente metaforizadas na mulher singular, forte, pura e sensual.

No Brasil, Flower foi lançado no mês de maio: a primavera européia, o mês das noivas e das mães brasileiro, além de, possivelmente, período de outras festividades internacionais que ignoramos. Eis a forma acabada do presente, que, por sua vez, será ainda embalado por outro tipo de invólucro tão sensorial e atrativo quanto este.

\section{Uma paixão recorrente - a relação com o dinheiro}

Há algumas semanas, a televisão tem apresentado uma peça publicitária da provedora Bol - Brasil On-Line utilizando a estratégia, já desgastada, da escolha do serviço pela condição mais econômica do preço.

Mais um dos recursos utilizados pela publicidade, a economia diz respeito à vantagem do produto, normalmente associada à manutenção da qualidade. Não se trata, portanto, como no exemplo acima, de firmar a diferença pelo status, pelo dispêndio, que se reitera no perfume sofisticado, no frasco com design arrojado, na embalagem artística e, por fim, no chamativo invólucro da loja (ou no nome da grife, o que já é suficiente numa sacola comum). A questão agora é justamente o contrário, consiste na sabedoria da retenção e não da ostentação.

O mote da publicidade consiste na máxima de que se você valoriza seu dinheiro, cuida para não perdê-lo. Valorizar, no exemplo, significa amar, e cuidar implica afagá-lo.

A peça apresenta uma mulher que passa delicadamente os dedos pelas notas de dinheiro, divide-as em seguida como se estivesse desfolhando as cédulas, passa-as enfim carinhosamente pelo rosto como se estivesse dando e recebendo um afago.

Tais demonstrações de carinho com o dinheiro, que atribuem às notas traços semânticos de valores animados, não é nova. Vários objetos já foram tratados dessa maneira na publicidade e, ao longo dos séculos, a história teatral e literária é pródiga em avarentos e usurários que manifestam sua paixão exacerbada pelas moedas. Em trabalho anterior (Caetano, 1997), pudemos analisar com mais detalhes dois exemplos da literatura universal, os personagens Fal- 
cão de Machado de Assis (histórias sem data) e Gobseck de Honoré de Baizac (Scènes de la vie privée). Falcão trata as moedas como objeto de amor, repassando às mesmas valores humanos. Em contrapartida, trata as sobrinhas como objetos de posse. Sonha com uma coleção de moedas, que imagina estar desarrumando, e, em seguida, volta a arranjá-las como "o amante que desgrenha a amada para toucá-la novamente". Gobseck coisifica as pessoas, porque vê nelas apenas quantidades de dinheiro. Sua aparência física vai se transformando com o tempo em características do objeto valorizado; os traços sensoriais do dinheiro como o cheiro das moedas, as cores do cobre, do ouro, da prata dão a configuração à sua tez, a voz vai se afinando em tons metálicos.

Essa passagem de valores humanos ao dinheiro, que se torna objeto de carinho, e de valores de posse aos seres humanos quantificados em somas de dinheiro são percursos narrativo-temáticos constantes na história das civilizações, porque representam a inauguração de um tipo de estrutura mercantil, que está na base econômica das sociedades modernas. Cada época, porém, discute o tema de maneira diferente, em função da estrutura social vivida, do papel atribuído ao dinheiro naquele momento histórico e da experiência pessoal dos autores com o tipo de conjuntura de que participam. Dessas circunstâncias decorrem também os tons de abordagem do fato: cômico ou trágico. Em Machado de Assis, o tom é cômico, a figura de Falcão torna-se motivo de riso porque corresponde a uma atitude extemporânea em relação a um Brasil já integrado às sociedades de estrutura comercial-industrial e financeira mundial. Em Balzac, o tom é dramático, porque prenuncia a nova sociedade de caráter capitalista-burguês que se consolida na França.

Na peça da Bol não temos nem um, nem outro caso. Trata-se apenas da naturalização de um processo, em que a reificação dos objetos obteve um tal grau de naturalização que parece absurdo qualquer destaque a respeito. De fato, justifica-se pela técnica da linguagem publicitária o uso da manobra discursiva. Para garantir o apelo sobre o consumidor, para torná-lo sensorialmente mais eficiente, várias estratégias são ativadas, entre elas a carícia nas notas que devem ser valorizadas, enunciando um processo de metaforização do bem possuído, equivalente ao bem amado. 
O princípio mobilizado para a significação das mensagens é o mesmo adotado pela publicidade do perfume da grife Kenzo, qual seja, a sobredeterminação de traços sensoriais para a construção de novos sentidos. Na verdade, em Kenzo, o percurso do olhar deflagra a relação tátil com a caixa da embalagem, correspondente, pode-se dizer, a uma certa forma de carícia do objeto que vai sendo cuidadosamente manipulado para ser contemplado em todas as suas partes. O consumidor, convertido em objeto de sedução, não se conscientiza do papel interativo que desempenha nesse ato de significação. As manobras para utilização desse princípio são porém distintas. No caso de Kenzo, a embalagem torna-se a representação simbólica do perfume e, por extensão, do usuário que nele se contempla de maneira narcisística; na peça da Bol, o dinheiro representa o objeto-valor contido na quantidade das notas que se acumulam nas mãos da protagonista. O ato de economizar é modalizado pelo saber (demonstra-se sabedoria ao procurar o produto mais barato), mas é também determinado pelo poder, pois desse procedimento é que resulta a possibilidade de reter as notas na posse do consumidor. Movimentos introjetivo de um lado e extrojetivo de outro, ambos conduzem a uma retenção aspectualizada do gesto para serem percebidos - o olhar e o toque. Mais do que falar à razão, evocam os afetos no trato dos seres humanos com os objetos e seus valores simbólicos, o que aliás confere expressividade e eficácia à linguagem da publicidade.

Não se pode dizer, porém, que a peça de Bol apresente o mesmo grau de criatividade e envolvimento do espectador obtido pela embalagem de Kenzo. A relação entre expressão e conteúdo é de uma redundância evidente. A gestualidade serve apenas para ilustrar a metáfora verbal (cuidar/poupar = afagar/amar), não exigindo qualquer tipo de concentração do leitor para acompanhar interativamente a construção do sentido dado. Talvez por isso também, a relação passional com o dinheiro apareça em sua manifestação mais empobrecida, a da necessidade da economia e a da banalização do afeto.

\section{A força centrípeta da imagem}

As peças de Oliviero Toscani, o criador das propagandas da Beneton, sempre causaram impacto sobre o público e tumulto no 
ambiente publicitário. Polêmico pelas criações que realiza e pelos discursos contundentes dirigidos a uma crítica da mediocrização da mídia, o artista prova a sua eficiência pelos saldos da balança comercial da Beneton desde que assumiu a responsabilidade de suas campanhas.

É desse autor a última peça escolhida para a presente discussāo, uma das mais controversas de suas produçōes e que angariou em vários países a proibição de sua circulação.

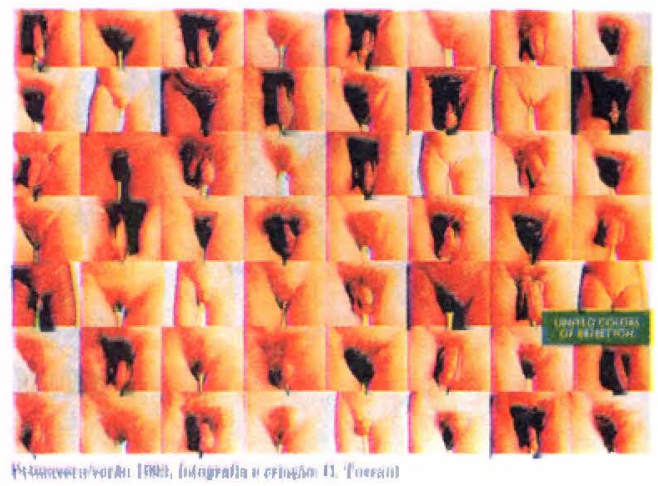

Figura 4 - Reprodução extraída da obra $A$ publicidade é um cadáver que nos sorri, 2000.

A escolha dessa propaganda deve-se à similaridade de procedimento que apresenta em relação aos dois exemplos anteriores. Não se trata de uma imagem a ser apreendida em seu todo, sob um olhar abrangente, que pode se disfarçar no simulacro do não-ver ou do não querer ver, embora vendo, que acontece com muitas cenas de exposição de nus.

O espectador é orientado a um percurso óptico, quadro a quadro, já que a peça está constituída da combinação sintática de diversas fotos de sexos masculinos e femininos. Isso lhe impõe duas alternativas: seja a de recusar, tout court, a sedução da foto, seja a de se entregar à trajetória proposta pelo criador e procurar para além das imagens os sentidos possíveis implícitos para um reatamento com o sentido geral do cartaz, que é de se anunciar como uma publicidade de empresa da moda.

Assim como a embalagem do perfume Flower, o outdoor da Beneton repousa sobre dois procedimentos similares da expres- 
são e do conteúdo. A articulação das imagens fotográficas, uma a uma, efetua um recorte na massa de seres humanos que se deixam individualizar pelos órgãos sexuais (de gêneros, idades e "tipos" diferentes). Trata-se pois do mesmo processo de discretização da imagem visual. Mas o agrupamento de fotos de sexos não permite a identificação dos rostos - a reprodução em seqüência linear acaba tendo um efeito contrário, o de igualdade dos seres ali retratados a despeito de suas individualidades. Aqui, as figuras da expressão discretização/linearidade remetem aos valores semânticos da categoria individualidade/igualdade, o que, de certo modo, simula descaracterizar o status social, a estética facial e a aparência do consumidor da grife.

Esse gênero de publicidade não reitera as imagens do mundo feliz, do cliente seguro ou satisfeito, do produto de qualidade, da aquisição econômica e do futuro tranqüilo registradas à exaustão no universo da propaganda. Não se pode dizer também que, para alguns, ela não esteja fortemente marcada por certo apelo erótico, daí talvez o caráter de nocividade que Ihes pareça apresentar.

$\mathrm{Na}$ verdade, quando analisada no intertexto de outras obras do autor, o caráter pressupostamente erótico se desfaz, uma vez que as peças de Oliviero procuram recuperar o papel de compromisso social que o meio publicitário pode explorar a despeito das finalidades últimas de sua existência. Na concepção do artista, o publicitário deve recorrer às potencialidades da mídia para contribuir com a formação de cabeças bem-feitas, questionando num processo metassemiótico a simulação de realidade criada pela própria publicidade. Sem entrar no mérito dessa discussão, que envolve, sem dúvida, uma armadilha argumentativa, o outdoor de Toscani expõe um processo criativo de relação com o enunciatário, que se vê convocado a interagir com o enunciado e sancioná-lo em sua intenção moral, e não propriamente midiática.

Vejamos qual é a explicação dada pelo próprio Toscani a respeito da idealização dessa criação:

Com a campanha sobre os órgãos sexuais de todas as idades e de todas as cores, bem enquadrados como fotomáticas, isolados em quadrados, de maneira clínica, 
como numa grande vitrine, deixei de lado a atualidade para voltar aos tabus. Com essas fotos eu me pergunto se podemos ser reconhecidos à simples vista de nossos sexos, como no caso do rosto. Um rosto fornece indicações de caráter, de destino, e até mesmo de origem social, mas ... e um sexo, apresentado como um retrato de identidade? Dificil.

l...

Mais uma vez, toda a imprensa européia me censurou. Na França, o Libération foi o único jornal a ousar publicar a página dupla. Ele teve uma venda espetacular, trinta mil exemplares a mais. Mesmo quando tirei essas fotos de sexo, todas simples, como uma coleção de acessórios, nunca cheguei à profunda baixeza de certas propagandas pseudo-eróticas, de numerosos espetáculos televisivos obscenos ou mesmo de políticos demagogos. O meu limite é a vulgaridade.

/...।

As imagens publicitárias constituem hoje uma parte imensa de nossa cultura, nossos conhecimentos, nosso gosto, nosso estilo, e inclusive nossa moral. O trabalho de um fotógrafo, de um artista, deve ser o de contribuir para $o$ renascimento da cultura, de levar para aí um sentimento crítico, um estilo desorientador, concepções novas, que os imbecis chamam sempre de escândalos.

l...

Se a publicidade é uma indústria, é também uma arte. (2000, p. 94-96)

Para tanto, a estratégia enunciativa é tratada em duas vertentes: de um lado, pela lógica do consenso ideológico, que faz apelo a certo tipo de público moderno, livre de preconceitos e contestador dos tabus e hipocrisia de nossa sociedade; de outro, pelo procedimento meticuloso de forçar o enunciatário a "sentir" as imagens acompanhando-as visualmente, talvez até mesmo em sua tactilidade, como se estivesse descortinando o lado oculto do que há de comum a todos os sujeitos. Um novo tipo de identidade é construído, perdido no anonimato das faces e das vestes e materializado na comunhão da di- 
versidade/igualdade do que é da natureza humana. $\mathrm{O}$ dispositivo empregado ganha a força manipulatória da provocação, que se define semioticamente como uma operação exercida sobre o outro pela modalidade do saber, sob a forma de um juizo negativo, que pode ser expresso na fórmula "você é incapaz de encarar essa imagem" ou outro juizo semelhante.

Segundo Greimas,

a manipulação caracteriza-se como uma ação do homem sobre outros homens, visando a fazê-los executar um programa dado: no primeiro caso, trata-se de um 'fazerser', no segundo, de um 'fazer-fazer'; essas duas formas de atividade, das quais uma se inscreve, em grande parte, na dimensão pragmática e a outra na dimensão cognitiva, correspondem assim a estruturas modais de tipo factitivo. (1979, p. 269)

A manipulação age pela persuasão, pois articula o fazer persuasivo do destinador ao fazer interpretativo do destinatário, que se vê inserido numa relação comunicativa contratual mediada seja pelo dever, no caso da provocação ou da intimidação, seja pelo querer, no caso da sedução ou da tentação.

O manipulador pode exercer seu fazer persuasivo apoiando-se na modalidade do poder: na dimensão pragmática, ele proporá então ao manipulado objetos positivos (valores culturais) ou negativos (ameaças); em outros casos, ele persuadirá o destinatário graças ao saber: na dimensão cognitiva, fará então com que ele saiba o que pensa de sua competência modal sob a forma de juizos positivos ou negativos. Vê-se, assim, que a persuasão segundo o poder caracteriza a tentação (em que é proposto um objeto-valor positivo) e a intimidação (em que é proposta uma doação negativa), enquanto a persuasão, segundo o saber, é própria da provocação (com um juizo negativo: 'Tu és incapaz de ...') e da sedução (que manifesta um juízo positivo). (p. 270) 
Evidentemente, o valor persuasivo da provocação só se realiza na medida em que a competência para a modalidade do saber é instituída, caso contrário a atitude do destinador-manipulador é interpretada como uma forma de intimidação (mais próxima à noção de provocação no senso comum), o que justifica a sanção cognitiva da maior parte dos enunciatários e a ação pragmática, de interdição do outdoor, do lado dos gestores da moral pública.

Chamar a atenção para algo que está fora da publicidade não é incomum. Ao contrário, essa tática constitui a essência desse tipo de linguagem, uma vez que ela se reporta à construção de imagens, e, por conseqüência, de auto-imagens. Por isso a máxima, que já é um truísmo nesse campo de estudo, de que não se vendem produtos e sim imagens. A fabricação de uma imagem insere-se no domínio da tentativa de fazer crer ser, ou seja, de se dar a idéia de pertença a um grupo, de formação de uma identidade com a qual, para o bem ou para o mal, tentamos nos identificar. Apenas desse ponto de vista, a peça publicitária de Toscani pode ser vinculada à divulgação do produto que vende: roupas. Em outros termos, o objeto converte-se em objeto-valor - torna-se signo de grupo - e confere uma existência semiótica particular àquele que o valoriza. Valorizálo não quer dizer necessariamente consumí-lo, mas reconhecer no sistema de circulação de valores na sociedade fatores de interação entre sujeitos que os assemelham em práticas e ideais comuns. $\mathrm{O}$ que a publicidade da Beneton mostra é que o elemento desencadeador desse imaginário comum não é sempre o objeto que se divulga, mas o tipo de interação obtida pela intervenção (definida modalmente como fazer-fazer) mediática estabelecida.

Assim como nas duas peças analisadas anteriormente, a maximização das potencialidades da mensagem deriva da exploração de uma linguagem sensorial responsável pelo mergulho/repúdio visual do espectador nas imagens. Interessa menos a perspectiva enunciva, nesse exemplo, voltada para a divulgação do produto, do que os efeitos de sentido de envolvimento do espectador, que pode apresentar reações positivas ou negativas ao enunciado. Nesse sentido, o texto joga mais com valores da ordem das emoções do que com o domínio da razão, que aparenta subsumir as escolhas de um produto (com afirmações do tipo estético, qualitativo etc.). 


\section{Razão ou afeto: a lógica dos paradoxos}

O fato de os três anúncios condicionarem sua eficácia sobre o destinatário com base no estímulo aos valores do afeto, mobilizados pela ação dos recursos sensoriais, parece predispô-los em igualdade de condições a uma lógica do mercado publicitário, em que tudo é válido, porque tudo é criatividade, a despeito do código de ética vigente.

No entanto, os códigos da linguagem são entrecruzados por códigos culturais diversos, e, se a metáfora desgastada pode ser renovada, e a reificação do dinheiro naturalizada, nem todos os nus têm aceitação pública. A publicidade de apelo erótico, com modelos masculinos e femininos semivestidos, divulgados em distintas mídias impressas e audiovisuais, que vão desde as revistas até os outdoors, passando por programas de televisão de público infantil, ou heterogêneo como o das telenovelas, já se enquadrou no padrão do aceitável em termos de visibilidade pública. Por mais explícitas que sejam, tais cenas são permitidas, ainda que façam fortes explorações de gestos ou práticas erotizadas, porque ocultam o último dos tabus ocidentais: a exposição dos órgãos sexuais. A perspectiva de Jean Baudrillard, de que vivemos sob o signo da simulação, justifica tal paradoxo, mas não esclarece completamente os motivos culturais de nossos juizos éticos e morais.

$\mathrm{O}$ argumento lógico para a rejeição de uma mensagem não apresenta, na verdade, nenhuma lógica. Totalmente apoiado em fatores emocionais que graduam as coisas e as práticas em termos de uma contínuo de limites fluidos entre os pólos opostos do aceitável e não-aceitável, do deficiente e excessivo, reiterando durante séculos um raciocínio pré-socrático bem evidente na Ética a Nicômacos de Aristóteles (1985), o discurso da razão resvala na criatividade da linguagem. Conforme Chomsky (1972) enunciou para o sistema lingüístico, podemos tratar a criatividade da linguagem nos termos de um jogo ambíguo, que possibilita dizer e desdizer, mostrar o visível e revelar o invisível, reiterar fórmulas cristalizadas dando-lhes novos efeitos e desvelar pelo gesto o que se contradiz pela fala.

Nas três peças comentadas, estão em jogo nas tramas discursivas (e não necessariamente na intenção dos idealizadores) 
os sentidos conotativos das mensagens, mobilizados constantemente pela cultura (ou o terceiro sentido barthesiano) e não apenas pela decodificação dos códigos. É contra ou na direção desse sentido obtuso descrito por Barthes que as emoções passionais se dirigem, mesmo quando travestidas em discursos carregados de objetividade. Estudar as relações intersubjetivas de comunicação implica, portanto, apreendê-las na multitude de significações que o conhecimento e a sensibilidade semiótica proporcionam sob o efeito das inflexōes culturais.

\section{Bibliografia}

A PUBLICIDADE É UM CADÁVER QUE NOS SORRI. 2000.

Rio de Janeiro: Ediouro, p. 64.

ARISTÓTELES. Ética a Nicômacos. Brasília: Ed. da UNB, 1985, livro IV.

BALZAC, H. De. Gobseck. Une double famille. Paris: Flammarion, 1984.

BARTHES, R. O óbvio e o obtuso. Ensaio sobre fotografia, cinema, pintura, teatro e música. Rio de Janeiro: Ed. Nova Fronteira, 1990.

. A aventura semiológica. São Paulo: Martins Fontes, 2001.

BARROS, D.L.P. de. Problemas de expressão: figuras de conteúdo e figuras de expressão. Anais do $1^{\circ}$ Colóquio Luso-Brasileiro de Semiótica. Universidade Federal Fluminense, 1986.

Texto e imagem. Linguagens. Porto Alegre: Revista da Regional Sul da Associação Brasileira de Semiótica, 01, out. 1986a, 29-38.

BAUDRILLARD, J. Simulacros e simulação. Lisboa: Relógio d'Agua, 1991.

CAETANO, K. E. Literatura e sociedade: a prática da análise de discursos. Campo Grande,MS: Ed. da UFMS, 1997.

CHOMSKY, N. O aspecto criador do uso da linguagem. In: Lingüística cartesiana. Petrópolis/São Paulo: Vozes/ EDUSP, 1972, p. 13-41. 
FLOCH, J.-M. Semiótica plástica e linguagem publicitária. Significação. Revista Brasileira de Semiótica. São Paulo: Centro de Estudos Semióticos, 6, jan. 1987, 29-50.

GREIMAS, A.-J. \& COURTÉS, J. Dicionário de semiótica. São Paulo: Cultrix, 1979.

GREIMAS, A.-J. \& FONTANILLE, J. Sémiotique des passions: des états des choses au états d'âme. Paris: 1991.

GREIMAS, A.-J. Semiótica figurativa e semiótica plástica. Significação. Revista Brasileira de Semiótica. Araraquara: Centro de Estudos Semióticos, 4, 1984, 18-46.

LIPPMANN, W. Estereótipos. In: STEINBERG, Ch. (org.). Meios de comunicação de massa. São Paulo: Cultrix, 1972, p. $149-$ 159.

MACHADO DE ASSIS, J. M. Obra completa. Rio de Janeiro: José Aguillar Ed., 1974, v. II. 